\title{
COMPARISON BETWEEN UV SPECTROPHOTOMETRY AND ANION EXCHANGE CHROMATOGRAPHY TECHNIQUES FOR QUANTIFICATION OF HEXENURONIC ACID (HEXA) IN UNBLEACHED KRAFT PULPS OF EUCALYPTUS GLOBULUS
}

\author{
MARIEL MONRROY, ${ }^{1,2}$ LORETO SANHUEZA, ${ }^{1}$ REGIS TEIXEIRA MENDONÇA, ${ }^{1,2, *}$ JAIME BAEZA ${ }^{1,3}$ AND \\ JUANITA FREER 1,3
}

\author{
${ }^{1}$ Renewable Resources Laboratory, Biotechnology Center, Universidad de Concepción, Casilla 160-C, Concepción, Chile. \\ ${ }^{2}$ Faculty of Forestry Sciences, Universidad de Concepción, Casilla 160-C, Concepción, Chile. \\ ${ }^{3}$ Faculty of Chemical Sciences, Universidad de Concepción, Casilla 160-C, Concepción, Chile.
}

(Received: October 29, 2008 - Accepted: )

\begin{abstract}
Two different methodologies were optimized for hexenuronic acid (HexA) quantification in E. globulus kraft pulps. In one, pulps were hydrolyzed with mercuric chloride/sodium acetate and quantified by ultraviolet spectrophotometry (UV technique); in the other one, the hydrolysis was performed with sulfuric acid and the degradation products of HexA quantified by anion exchange chromatography (AEC technique). In order to determine the optimal conditions for maximum removal of HexA from pulps by acid hydrolysis, the variables time, $\mathrm{pH}$, and temperature were studied. The influences of these three variables were determined by means of a response surface methodology (RSM). The optimized conditions for the hydrolysis by the UV technique were: 45 min, $\mathrm{pH} 5.7$ and $80^{\circ} \mathrm{C}$. While, for hydrolysis using the AEC technique, the optimized conditions were: $3.1 \mathrm{~h}, \mathrm{pH} 0.7$ and $97^{\circ} \mathrm{C}$. Both AEC and UV methods presented good reproducibility with $2.1 \%$ and $1.4 \%$ relative standard deviation (RSD), respectively. However, HexA values measured by the AEC technique method were $11-30 \%$ lower than those measured using the UV technique. For additional information, five selected pulps were analyzed by other methods, known as KTH and HUT. The results obtained by the four methods employed showed significant variations in the HexA quantification. The highest HexA values were obtained using the UV technique. The KTH, AEC and HUT methods provided HexA amounts in 7-16\%, 17-24\% and 24-30\% lower than the values obtained by UV method, respectively, for the same set of pulps. The UV technique is more susceptible to be interfered with pulp hydrolysis byproducts, attributed mainly to lignin solubilization, while the AEC technique allows direct measurement of HexA hydrolysis products without interference from other compounds.
\end{abstract}

Keywords: Eucalyptus globulus, kraft pulping, hexenuronic acids, UV spectrophotometry, anion exchange chromatography.

\section{INTRODUCTION}

Hemicelluloses are one of the three main components of lignocellulosic materials, where cellulose and lignin are the other two. Their amount and structure were reviewed by Ebringerová et al. ${ }^{1}$. The delignification of wood during chemical pulping processes is also accompanied by the simultaneous dissolution and degradation of carbohydrates, especially hemicelluloses ${ }^{2}$. During kraft pulping, 4- $O$-methyl- $\alpha$-D-glucuronic acid (MeGlcA) groups present in xylan chains of the hemicelluloses are partially converted into hexenuronic acid (HexA) depending on the cooking conditions, such as hydroxyl ion concentration, pulping time and temperature ${ }^{3-7}$. HexA formation is more pronounced in hardwoods than in softwoods due to the large amount of acetyl-4-O-methylglucuronoxylan in the hemicellulose composition of hardwood species ${ }^{8}$.

HexA quantification is important in alkaline pulping processes because it interferes in the method when determining residual lignin in unbleached pulps (known as kappa number) and may contribute to an erroneous overestimation of lignin content that could affect bleaching chemicals calculation and consumption ${ }^{7,9,10}$. Due to its double bound functionality, HexA react with and consume electrophilic bleaching chemicals, such as chlorine dioxide, ozone and peracids. HexA also reduces the pulp's brightness stability and can cause yellowing of the paper ${ }^{5,7,11-13}$.

Several analytical methods for quantification of HexA in softwood and hardwood kraft pulps have been proposed. Vuorinen et al. ${ }^{7}$ proposed a method for HexA measurement in kraft pulps, referred as the HUT method, based on the selective hydrolysis of HexA with sodium formate buffer, followed by UV spectrophotometric detection at $245 \mathrm{~nm}$. Although, this is a rapid method, it can present interference from substances such as the acid-soluble fraction of residual lignin that can also present UV absorption at the selected wavelength ${ }^{14}$. Other methods used for HexA quantification involve pulp hydrolysis with cellulolytic and hemicellulolytic enzyme mix, followed by chromatographic and/or spectroscopic analysis of the hydrolysates, using anion exchange chromatography coupled with amperometric pulse detection ${ }^{15}$, capillary zone electrophoresis (CZE) ${ }^{16}$ and nuclear magnetic resonance (also referred as VTT method) ${ }^{17}$. The enzymatic method is very time consuming (at least two days) due to the low enzymatic hydrolysis rate of pulps. Gellerstedt \& $\mathrm{Li}$ ${ }^{10}$ developed a method to determine HexA by HPLC using a combination of hydrolysis with mercury acetate, oxidation with periodate, and reaction with thiobarbituric acid to form a colored structure (TBA- $\beta$-formyl pyruvic acid adduct), which could be determined by chromatographic separation (named as
KTH method). The hydrolysis of HexA by the KTH method is very efficient; however, it requires several experimental steps before the quantification of the hydrolysis products.

Another method developed to determine HexA in kraft pulps was based on selective hydrolysis of the pulp with sulfuric acid to degrade HexA to 2-furancarboxylic acid (FA) and 5-formyl-2-furancarboxylic acid (FFA) followed by the quantification of the products by anion exchange chromatography (AEC) ${ }^{14}$. The detection of degradation products of HexA hydrolysis using the AEC technique was compared with detection with CZE (on the same pulp hydrolysate), finding a good agreement between both techniques with respect to the similarity of the quantification results. Chai et al. ${ }^{9}$ also described a fast and simple method to determine HexA amount in kraft pulps, in which pulp hydrolysis is performed with mercuric chloride and sodium acetate solution and the quantification of products performed by UV spectrophotometry at two wavelengths $(260$ and $290 \mathrm{~nm})$. The HexA content was calculated by an equation that includes correction factors for the spectral contribution of lignin and eliminates possible measurement errors due to spectral background shift in absorption experiments.

The effect of HexA groups and the benefit of their removal from unbleached pulps depend on their content in the pulp as well as on the bleaching sequence used. Reasonable, reliable, and simple methods to quantify HexA in kraft pulps are needed.

The aim of this work was to compare and to optimize two quantification methods for HexA in E. globulus kraft pulps. One is based in the hydrolysis of the pulps with mercuric chloride/sodium acetate and quantification of the products by UV spectrophotometry, and the other is based in the hydrolysis with sulfuric acid and quantification of the products by anion exchange chromatography. The reproducibility of both methods was also evaluated. In order to compare, some samples were also analyzed by KTH and HUT methods.

\section{EXPERIMENTAL}

\section{Kraft pulping}

Kraft pulping was performed by cooking industrial-size wood chips $(2.5 \mathrm{x}$ $1.5 \times 0.2 \mathrm{~cm}$ ) from $10-12$ years old E. globulus provided by a local pulp mill. Wood chips were well mixed to create a single uniform sample, air-dried and stored in dry conditions before use. The samples were cooked in a $1000 \mathrm{~mL}$ Parr reactor (Parr Instrument Co., Moline, IL, USA) loaded with $50 \mathrm{~g}$ of wood chips (dry basis) and a liquor:wood ratio of 5:1 (v/w). Cooking liquor composition was $12 \%, 15 \%$ or $20 \%$ active alkali (AA) and $25 \%$ of sulfidity (both calculated 
on dry wood basis and expressed as $\mathrm{Na}_{2} \mathrm{O}$ equivalents). The reactor was heated at $1.6^{\circ} \mathrm{C} \mathrm{min}^{-1}$ and pulping experiments were performed at two different temperatures, $155^{\circ} \mathrm{C}$ and $165^{\circ} \mathrm{C}$. Cooking time was $15,30,60,120,180,240$ or 300 min to produce pulps with different amounts of residual lignin and HexA. A total of $135 \mathrm{kraft}$ pulps were prepared as a result of the combination of the different pulping conditions used ( $3 \mathrm{AA} \times 2$ temperatures $\times 7$ cooking time, in triplicate, plus 9 additional pulps produced as a fourth repetition of some of the conditions). After cooking, pulps were disintegrated in a TAPPI laboratory blender, thoroughly washed with tap water, and centrifuged. Total pulp yield was determined based on the weight of the pulp divided by wood chips weight (both on dry basis) multiplied by $100 \%$.

\section{Quantification of HexA}

\section{UV-technique}

HexA content in kraft pulps was quantified based in the dual-wave UV spectrophotometry analysis published by Chai et al. ${ }^{9}$ Approximately $50 \mathrm{mg}$ of air-dried pulp with known moisture content was weighed and placed in a 20 $\mathrm{mL}$ vial containing $10 \mathrm{~mL}$ of the hydrolysis solution ( $0.6 \%$ of mercuric chloride and $0.7 \%$ of sodium acetate). The experimental conditions were $45 \mathrm{~min}$ of reaction time, $\mathrm{pH} 5.7$ and $80^{\circ} \mathrm{C}$. These conditions were selected following a full factorial design (Table 1) with the aim to obtain the maximum hydrolysis of HexA. After each reaction, the solution was cooled to room temperature, filtered through a nitrocellulose filter $(0.22 \mu \mathrm{m}$ pore $)$, and the UV absorption of the solution was measured at two wavelengths, $260 \mathrm{~nm}$ and $290 \mathrm{~nm}$. The products of the acidic degradation of HexA are 2-furancarboxylic acid (FA) and 5-formyl-2-furancarboxylic acid (FFA). The fresh hydrolysis solution was used as a blank for the UV absorption measurements. The HexA content was calculated using the dual-wavelength equation (Eq. 1) as proposed by Chai et al. ${ }^{9}$, where $C_{\text {HexA }}$ is the concentration of HexA in pulp ( $\mathrm{mmol} \mathrm{kg}^{-1}$ of pulp); 0.287 is the calibration factor for the dual-wavelength method; $A_{260}$ and $A_{290}$ are the measured absorption intensities at $260 \mathrm{~nm}$ and $290 \mathrm{~nm}$, respectively; 1.2 is the ratio of lignin absorption at the two wavelengths; $V$ is the volume of the hydrolysis solution $(\mathrm{mL})$ and $w$ is the oven-dried weight of the pulp sample (g.)

$$
C_{H e x A}=0.287 \frac{\left(A_{260}-1.2 A_{290}\right) V}{w}
$$

\section{AEC technique}

This method was firstly proposed by Jiang et al.${ }^{14}$ Approximately $100 \mathrm{mg}$ of air-dried pulp with known moisture content was weighed and placed in a $20 \mathrm{~mL}$ vial containing $10 \mathrm{~mL}$ of a diluted sulphuric acid solution. The hydrolysis was carried out at the optimum experimental conditions at $97^{\circ} \mathrm{C}, \mathrm{pH} 0.7$ and 3.1 $\mathrm{h}$ determined by a full factorial design (Table 1 ) for the maximum hydrolysis of HexA. The hydrolysate was filtered through a nitrocellulose filter $(0.22 \mu \mathrm{m}$ pore), and diluted 10 times with $4 \mathrm{mM}$ sodium hydroxide. The solution was analyzed by AEC with suppressed conductivity detection. Hydrolysis products (FA and FFA) were separated on an AS11 $4 \mathrm{~mm}$ analytical column with an AG11 $4 \mathrm{~mm}$ guard column (Dionex), using $4 \mathrm{mM}$ sodium hydroxyde as eluent delivered at $0.7 \mathrm{~mL} \mathrm{~min}^{-1}$. The HexA content was calculated using calibration curves for standards of two hydrolysis products of the HexA degradation at concentrations of 1 to $4 \mathrm{mg} \mathrm{L}^{-1}$.

\section{Quantification of hexenuronic acids by HUT and KTH methods}

Other methods found in the literature were also used to quantify the HexA in some selected pulps in order to compare the results obtained by the previous optimized methodologies. These methods were named HUT, proposed by Vuorinen et al. ${ }^{7}$, and $\mathrm{KTH}$, proposed by Gellerstedt \& $\mathrm{Li}^{10}{ }^{10}$ In the first, approximately $330 \mathrm{mg}$ of air-dried pulp (with known moisture content) was treated with $10 \mathrm{~mL}$ of $10 \mathrm{mM}$ sodium formate buffer solution at $110^{\circ} \mathrm{C}$ by $1 \mathrm{~h}$, followed by UV spectrophotometric detection at $245 \mathrm{~nm}$ (molar absorptivity = $10.8 \times 10^{3} \mathrm{~L} \mathrm{~mol}^{-1} \mathrm{~cm}^{-1}$ ). The KTH method was based on the hydrolysis of 250 $\mathrm{mg}$ of pulp in a test tube containing $7.5 \mathrm{~mL}$ of water and $7.5 \mathrm{~mL}$ of $70 \mathrm{mM}$ mercuric acetate solution. The reaction is carried out during $20 \mathrm{~min}$ at room temperature and filtrated. Then, $300 \mu \mathrm{L}$ of the filtrate were acidified with 60 $\mu \mathrm{L}$ of concentrated $\mathrm{HCl}$ and immediately oxidized with $0.5 \mathrm{~mL}$ of periodate solution $(0.1 \mathrm{mM}$ sodium metaperiodate in $2.8 \mathrm{M}$ phosphoric acid) during $20 \mathrm{~min}$ at room temperature. The resulting solution was treated with $2 \mathrm{~mL}$ of arseniate solution (4\% sodium arseniate in $0.5 \mathrm{M}$ hydrochloric acid) until the brown color disappeared. Thiobarbituric acid $(0.3 \%$ in water) was added to the test tube to a total volume of $10 \mathrm{~mL}$. The tube was heated at $50^{\circ} \mathrm{C}$ in a water bath for 170 min resulting in the TBA- $\beta$-formyl pyruvic acid adduct. An aliquot of $100 \mu \mathrm{L}$ of the red-colored adduct formed was separated in a Licrocart
250-4 (RP-18) column using $0.5 \%$ of trifluoroacetic acid aqueous solution as mobile phase for $5 \mathrm{~min}$, followed by a linear gradient of methanol-water mixtures containing $0.5 \%$ of trifluoroacetic acid (from 0 to $100 \%$ methanol in $14 \mathrm{~min}$ ) at a flow rate was $0.8 \mathrm{~mL} \mathrm{~min}^{-1}$. The TBA-adduct was monitored at $549 \mathrm{~nm}$ and quantified through a calibration curve using ammonium 3-deoxy2-keto-octonate as standard. The standard $(1.0 \mathrm{mg} \pm 0.1)$ was dissolved in 1 $\mathrm{mL}$ of water, and $20,40,80$, and $160 \mu \mathrm{L}$ aliquots were taken and dissolved in $1 \mathrm{~mL}$ of $35 \mathrm{mM}$ mercuric acetate. All solutions were subsequently treated with periodate, arsenite, and TBA as described above and analyzed for the TBA-3formyl pyruvic acid adduct.

\section{Response surface methodology}

In order to determine the conditions to obtain maximum HexA hydrolysis from the pulps, the variables $\mathrm{pH}$, time and temperature were studied. To determine these conditions, one single pulp with high HexA content was used (49 mmol kg-1 pulp based in UV determination). The influences of these three variables were determined using response surface methodology (RSM). ${ }^{18}$ This model is based on a central composite circumscribed design made of a factorial design and star points. The variable values were coded and normalized in unitary values: -1 was defined as the lowest value of a variable and +1 was defined as the highest value. From the extreme variable values, the central point (coded 0) was set and assayed in triplicate. Four star points distributed at a distance of 1.68 from the central point were included. The complete experimental design for the reaction conditions of the two methods optimized for HexA quantification is presented in Table 1.

A second-order function that best describes the system behavior was determined by a multiple lineal regression method (MLR). The statistical validation was performed by a one-way ANOVA test with $95 \%$ confidence level. The optimal conditions values were determined based on the response surface calculated using the SIMPLEX method. ${ }^{18}$ All the calculations were performed with the software Modde 7.0.0.1 (Umetrics, USA).

Table 1. Optimization experimental design for HexA hydrolysis of kraft pulp.

\begin{tabular}{|c|c|c|c|c|c|c|}
\hline \multirow{2}{*}{ Run } & \multicolumn{3}{|c|}{ UV } & \multicolumn{3}{|c|}{ AEC } \\
\cline { 2 - 7 } & $\mathbf{T}\left({ }^{\circ} \mathbf{C}\right)$ & $\mathbf{p H}$ & $\begin{array}{c}\text { Time } \\
(\mathbf{m i n})\end{array}$ & $\mathbf{T}\left({ }^{\circ} \mathbf{C}\right)$ & Time (h) & $\mathbf{p H}$ \\
\hline $\mathbf{1}$ & $65(-1)$ & $4(-1)$ & $25(-1)$ & $80(-1)$ & $2(-1)$ & $1(-1)$ \\
\hline $\mathbf{2}$ & $95(1)$ & $4(-1)$ & $25(-1)$ & $110(1)$ & $2(-1)$ & $1(-1)$ \\
\hline $\mathbf{3}$ & $65(-1)$ & $6(1)$ & $25(-1)$ & $80(-1)$ & $4(1)$ & $1(-1)$ \\
\hline $\mathbf{4}$ & $95(1)$ & $6(1)$ & $25(-1)$ & $110(1)$ & $4(1)$ & $1(-1)$ \\
\hline $\mathbf{5}$ & $65(-1)$ & $4(-1)$ & $65(0)$ & $80(-1)$ & $2(-1)$ & $2(1)$ \\
\hline $\mathbf{6}$ & $95(1)$ & $4(-1)$ & $65(0)$ & $110(1)$ & $2(-1)$ & $2(1)$ \\
\hline $\mathbf{7}$ & $65(-1)$ & $6(1)$ & $65(0)$ & $80(-1)$ & $4(1)$ & $2(1)$ \\
\hline $\mathbf{8}$ & $95(1)$ & $6(1)$ & $65(0)$ & $110(1)$ & $4(1)$ & $2(1)$ \\
\hline $\mathbf{9}$ & $55(-1.68)$ & $5(0)$ & $45(0)$ & $70(-1.68)$ & $3(0)$ & $1.5(0)$ \\
\hline $\mathbf{1 0}$ & $105(1.68)$ & $5(0)$ & $45(0)$ & $120(1.68)$ & $3(0)$ & $1.5(0)$ \\
\hline $\mathbf{1 1}$ & $80(0)$ & $3.3(-1.68)$ & $45(0)$ & $95(0)$ & $1.3(-1.68)$ & $1.5(0)$ \\
\hline $\mathbf{1 2}$ & $80(0)$ & $6.7(1.68)$ & $45(0)$ & $95(0)$ & $4.7(1.68)$ & $1.5(0)$ \\
\hline $\mathbf{1 3}$ & $80(0)$ & $5(0)$ & $11(-1.68)$ & $95(0)$ & $3(0)$ & $0.7(-1.68)$ \\
\hline $\mathbf{1 4}$ & $80(0)$ & $5(0)$ & $79(1.68)$ & $95(0)$ & $3(0)$ & $2.3(1.68)$ \\
\hline $\mathbf{1 5}$ & $80(0)$ & $5(0)$ & $45(0)$ & $95(0)$ & $3(0)$ & $1.5(0)$ \\
\hline $\mathbf{1 6}$ & $80(0)$ & $5(0)$ & $45(0)$ & $95(0)$ & $3(0)$ & $1.5(0)$ \\
\hline $\mathbf{1 7}$ & $80(0)$ & $5(0)$ & $45(0)$ & $95(0)$ & $3(0)$ & $1.5(0)$ \\
\hline
\end{tabular}




\section{RESULTS AND DISCUSSION}

The chemical composition of the E. globulus wood chips used in this work was: $49.6 \%$ glucan, $16.1 \%$ xylan, $26.3 \%$, lignin, $5.3 \%$ MeGlcA and $1.2 \%$ extractives. The wood chips were cooked in a batch kraft process using different pulping conditions with the aim to produce pulps with different degrees of delignification and amounts of hexenuronic acids. Table 2 presents the range of values for the pulp characteristics evaluated.

HexA compounds containing enol ether or unsaturated carboxylic acid groups that are unstable in mild acidic solutions and generate distinct degradation products according to the hydrolysis conditions used (Figure 1) $7,10,14$

Table 2. Pulp yield and chemical composition ranges of E. globulus kraft pulps.

\begin{tabular}{|l|c|c|c|c|c|c|}
\hline & $\begin{array}{c}\text { Lignin } \\
(\%)\end{array}$ & $\begin{array}{c}\text { Kappa } \\
\text { number }\end{array}$ & $\begin{array}{c}\text { Glucan } \\
(\%)\end{array}$ & $\begin{array}{c}\text { Xylan } \\
(\%)\end{array}$ & $\begin{array}{c}\text { MeGlcA } \\
(\mathbf{m m o l} / \\
\mathbf{k g})\end{array}$ & $\begin{array}{c}\text { Pulp } \\
\text { yield } \\
(\%)\end{array}$ \\
\hline $\begin{array}{l}\text { Minimum } \\
\text { content }\end{array}$ & 1.4 & 8.5 & 64 & 12.0 & 220 & 46 \\
\hline $\begin{array}{l}\text { Maximum } \\
\text { content }\end{array}$ & 18.0 & 62.4 & 77 & 18.0 & 360 & 70 \\
\hline Average std & 0.3 & 0.6 & 0.7 & 0.3 & 10.3 & 1.2 \\
\hline
\end{tabular}

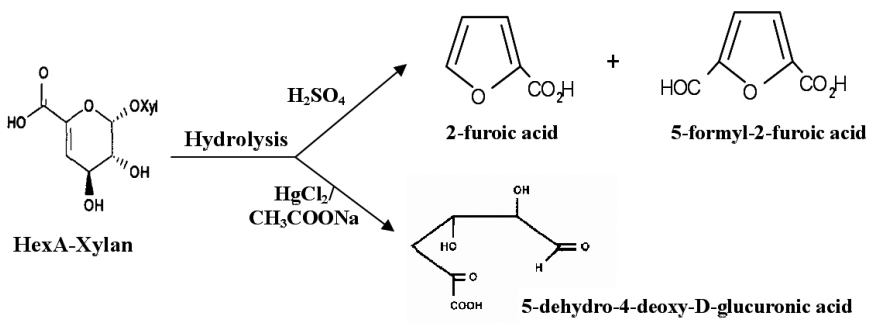

Figure 1. Products generated from the mild acid hydrolysis of HexA present in kraft pulps.

\section{Quantification of HexA by UV-technique}

This methodology utilizes mercuric chloride and sodium acetate as hydrolysis solution. Mercuric chloride can selectively hydrolyze hexenuronic acid groups from pulp (Gellerstedt \& Li, 1996). Additionally, since mercuric chloride is stable and has a relatively low absorptivity in the UV range especially at wavelengths above $250 \mathrm{~nm}$, direct UV absorption spectroscopy can be applied for HexA determination ${ }^{9}$. To evaluate hydrolysis conditions, screening by means of factorial design was developed, varying the temperature, time and $\mathrm{pH}$ of reaction.

From the experimental design data (Table 1) and its corresponding HexA concentration determined by using the equation (Eq. 1) proposed by Chai et al. ${ }^{9}$, whose results are presented in Table 3, a quadratic polynomial was determined (Eq. 2) and validated by the ANOVA test.

$\mathbf{Y}=7.58 \pm 0.35-0.04 \pm 0.16 \mathbf{X}_{1}+0.83 \pm 0.16 \mathbf{X}_{2}+0.36 \pm 0.16 \mathbf{X}_{3}-0.35 \pm 0.18 \mathbf{X}_{1}{ }^{2}$ $-0.55 \pm 0.18 \mathbf{X}_{2}^{2}-0.33 \pm 0.18 \mathbf{X}_{3}^{2}$

where $\mathrm{X}_{1}$ is the temperature $\left({ }^{\circ} \mathrm{C}\right), \mathrm{X}_{2}$ is the $\mathrm{pH}, \mathrm{X}_{3}$ is the reaction time (min) and $\mathrm{Y}$ is the HexA content (mmol kg-1 pulp). The coefficients have been normalized in order to compare the relative importance of the model's variables. The error values corresponded to a $95 \%$ confidence level. The response surface for the polynomial (plot inside the dominium limited for the experimental planning) is shown in Figure 2.

The linear terms for $\mathrm{pH}$ and reaction time have positive coefficients, meaning that the response incremented with the increase in these variables. The temperature did not contribute as a linear term. Quadratic terms for all variables are negative, indicating the presence of maximum values for each variable. Considering the confidence intervals, the interaction between variables did not have a significant effect on the HexA hydrolysis. The variable $\mathrm{pH}$ is the main factor for HexA hydrolysis according to the polynomial. The hydrolysis solution seems be more effective near the neutral range.

Based in the experimental conditions used in the experimental design, the polynomial was used to predict the amount of HexA. The responses were close to the experimental values (Table 3) with a correlation coefficient $\left(\mathrm{r}^{2}\right)=0.95$. These values together with the ANOVA test provided a statistical validation of the model.

The optimum values of the variables for hydrolysis of the HexA were determined by the SIMPLEX method using the maximum values of the response surface ${ }^{18}$. The predicted values were: $45 \mathrm{~min}, \mathrm{pH} 5.7$ and $80^{\circ} \mathrm{C}$. According to the polynomial, the response was $51.3 \pm 1.7 \mathrm{mmol} \mathrm{kg}^{-1}$ pulp for the pulp employed in the experimental design. The experimental HexA hydrolysis for this pulp obtained at these conditions was $50.6 \pm 0.3 \mathrm{mmol} \mathrm{kg}^{-1}$ pulp, agreeing with the predicted value.

\section{Quantification of HexA by AEC-technique}

For HexA determination by AEC, pulps were hydrolyzed with sulfuric acid solution because other hydrolysis solutions such as formic or trifluoroacetic acid causes interference during the detection of the degradation products of HexA by chromatography ${ }^{14}$. The hydrolysis solution used in the UV technique cannot be employed because chloride also presents a peak signal superimposed with the peaks of the hydrolysis products of the HexA degradation. Thus, kraft pulps were hydrolyzed with sulfuric acid and the hydrolyzate was analyzed by AEC under reproducible and validated chromatographic conditions. The compounds FA and FFA were separated with great efficiency with retention times of $7.68 \pm 0.07 \mathrm{~min}$ and $9.77 \pm 0.14$, respectively. The relative standard deviation (RSD) for several analyses done in triplicate was smaller than $2 \%$ and the quantification limit was $0.40 \mathrm{ppm}$ for both compounds in the chromatographic conditions used.

In order to determine the optimal conditions of HexA hydrolysis, the response surface methodology was also used. In the experimental design, the temperature, reaction time and $\mathrm{pH}$ were varied. The same pulp used for UV quantification was used in AEC quantification of HexA. From the experimental design data (Table 1) and its corresponding HexA concentration (Table 3), a quadratic polynomial was determined (Eq. 3) and validated by the ANOVA test.

$$
\begin{aligned}
\mathbf{Y} & =3.64 \pm 0.18+0.49 \pm 0.11 \mathbf{X}_{1}-0.30 \pm 0.11 \mathbf{X}_{2}+0.19 \pm 0.11 \mathbf{X}_{3}-0.93 \pm 0.12 \mathbf{X}_{1}{ }^{2} \\
-0.32 \pm 0.12 \mathbf{X}_{2}^{2} &
\end{aligned}
$$

where $\mathrm{X}_{1}$ is the temperature $\left({ }^{\circ} \mathrm{C}\right), \mathrm{X}_{2}$ is the $\mathrm{pH}, \mathrm{X}_{3}$ is the reaction time and $\mathrm{Y}$ is the HexA content ( $\mathrm{mmol} \mathrm{kg}^{-1}$ pulp). The coefficients have been normalized in order to compare the relative importance of the model's variables. The error values corresponded to a $95 \%$ confidence level.

The linear terms for temperature and hydrolysis time with positive coefficients indicated that the response increases with increases in temperature and time. The $\mathrm{pH}$ shows a negative coefficient, meaning that the response decreases with the increase in $\mathrm{pH}$. Only the quadratic term for temperature and time are important, indicating the presence of a maximum value for the variable. Considering the confidence intervals, the variable temperature is the main factor for HexA hydrolysis by this procedure. The polynomial predicted responses that were close to the experimental values (Table 3) with a correlation coefficient $\left(\mathrm{r}^{2}\right)=0.97$. These values together with the ANOVA test provided a statistical validation for the model. The response surface polynomial is shown in Figure 3.

The optimum values of the variables for HexA hydrolysis were determined by the SIMPLEX method from the maximum values of the response surface. The predicted values were $3.1 \mathrm{~h}, \mathrm{pH} 0.7$ and $97^{\circ} \mathrm{C}$. According to the polynomial, the response was $35.5 \pm 1.6 \mathrm{mmol} \mathrm{kg}^{-1}$ pulp. The experimental HexA hydrolysis obtained at these conditions was $36.5 \pm 0.2 \mathrm{mmol} \mathrm{kg}{ }^{-1}$ pulp for the pulp employed in the experimental design, agreeing with the predicted values from the polynomial.

HexA measured by the AEC method were $22 \%$ lower than those measured by the UV method. This variation in the determination may be due to possible interference of other compounds in the pulp hydrolyzate that can also absorb UV light at the same wavelengths used to measure hydrolysis products. On the other hand, the AEC technique allows direct quantification of the HexA hydrolysis products, reducing interference and increasing the accuracy of HexA quantification. Under the applied conditions, approximately the $95 \%$ of HexA groups are hydrolyzed for both techniques in. That was determined by applying at least three successive hydrolysis for the same pulp in the optimal conditions and measuring the amount of HexA formed in each one. The use of same hydrolysis for both methods is difficult, because for HexA determination 
by AEC technique, chloride in the hydrolysis solutions affects the hydrolysis products' chromatographic signal and in the UV technique, the sulfuric acid solution could facilitate the lignin hydrolysis affecting quantification of HexA.

Table 3. Experimental and calculated HexA (mmol $\mathrm{kg}^{-1}$ pulp) content values by the response polynomial.

\begin{tabular}{|c|c|c|c|}
\hline \multicolumn{2}{|c|}{ UV } & \multicolumn{2}{c|}{ AEC } \\
\hline $\begin{array}{c}\text { Experimental } \\
\text { HexA }\end{array}$ & $\begin{array}{c}\text { Calculated } \\
\text { HexA }\end{array}$ & Experimental HexA & $\begin{array}{c}\text { Calculated } \\
\text { HexA }\end{array}$ \\
\hline 32.3 & 33.9 & 15.0 & 16.9 \\
\hline 34.6 & 33.3 & 27.1 & 25.2 \\
\hline 47.4 & 44.7 & 18.6 & 20.2 \\
\hline 44.6 & 44.1 & 28.4 & 28.5 \\
\hline 39.0 & 38.6 & 13.3 & 12.3 \\
\hline 37.5 & 37.9 & 22.0 & 20.6 \\
\hline 50.7 & 49.4 & 16.8 & 15.6 \\
\hline 46.0 & 48.8 & 24.8 & 23.9 \\
\hline 42.0 & 43.4 & 2.8 & 1.7 \\
\hline 43.5 & 42.5 & 13.6 & 15.6 \\
\hline 30.5 & 30.1 & 19.5 & 20.5 \\
\hline 47.4 & 50.2 & 26.2 & 26.1 \\
\hline 37.7 & 39.3 & 36.2 & 35.0 \\
\hline 48.3 & 47.2 & 24.9 & 27.2 \\
\hline 50.1 & 49.3 & 30.3 & 31.1 \\
\hline 49.5 & 49.3 & 31.5 & 31.1 \\
\hline 48.5 & 49.3 & 31.9 & 31.1 \\
\hline & & & \\
\hline
\end{tabular}

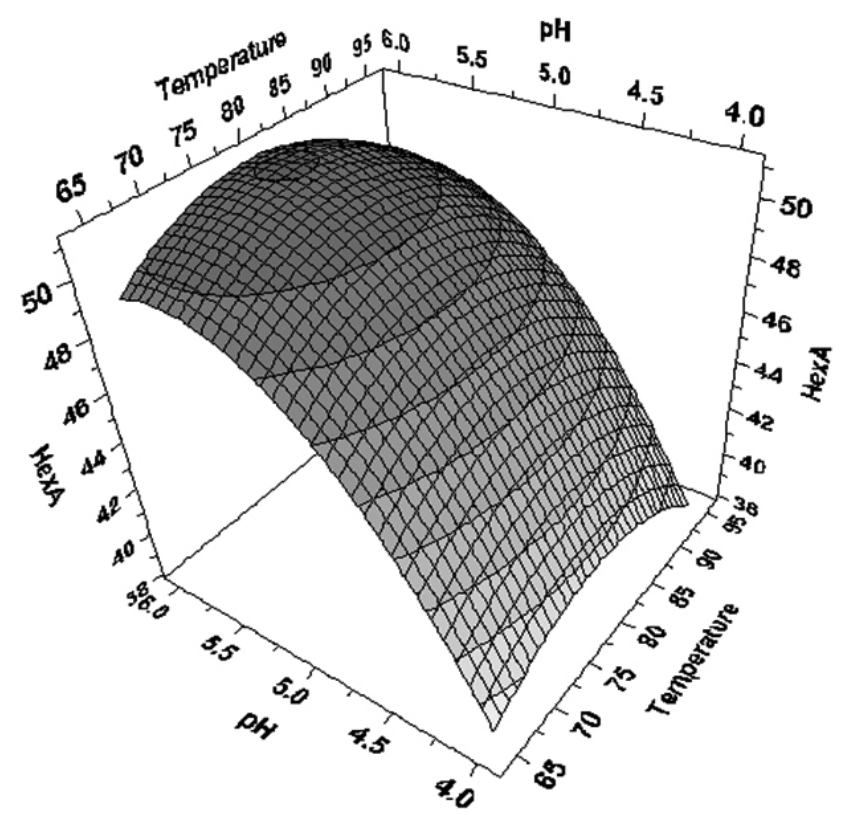

Figure 2. Surface response for the hydrolysis of HexA in E. globulus kraft pulps determined by UV spectrophotometric method.

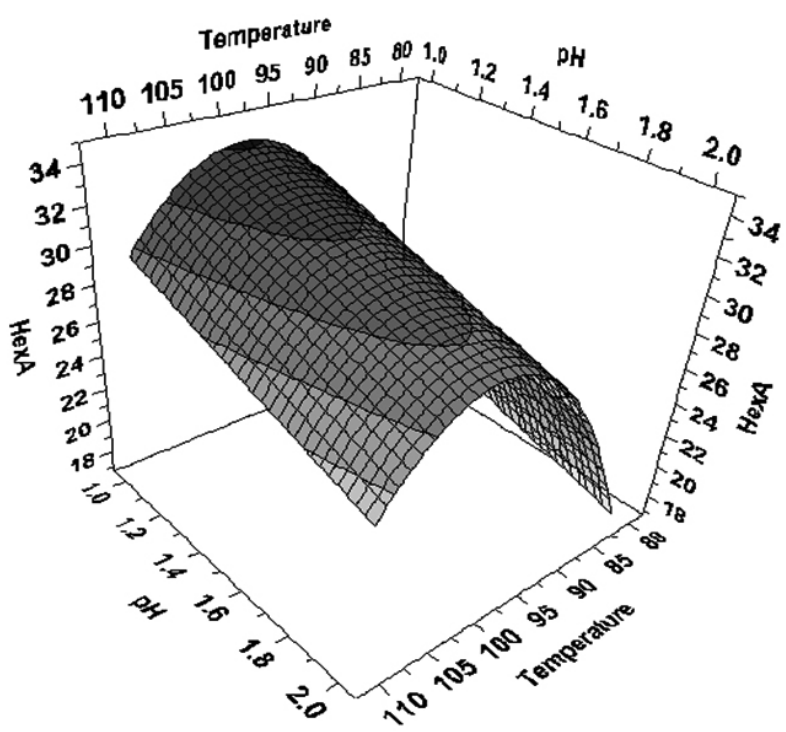

Figure 3. Surface response for the hydrolysis of HexA in E. globulus kraft pulps determined by anion exchange chromatographic method.

Quantification of HexA in kraft pulps by spectrophotometric and chromatographic optimized methods

With the optimum hydrolysis conditions determined for each methodology, all the $135 \mathrm{kraft}$ pulps produced were hydrolyzed and analyzed by both techniques. In this work, we observed that the values of HexA in pulps by AEC technique were lower than the values obtained by UV (Figure 4). It is important to clarify that HexA quantification by UV method was obtained with the equation developed by Chai et al. ${ }^{9}$, which has a factor used to correct for lignin interference. This equation was developed using a pulp characterized firstly by the KTH method and then used in the calibration for UV, which indicates that the accuracy of the UV present method is greatly dependent on the accuracy of the original value for the standard pulp obtained by the KTH method.

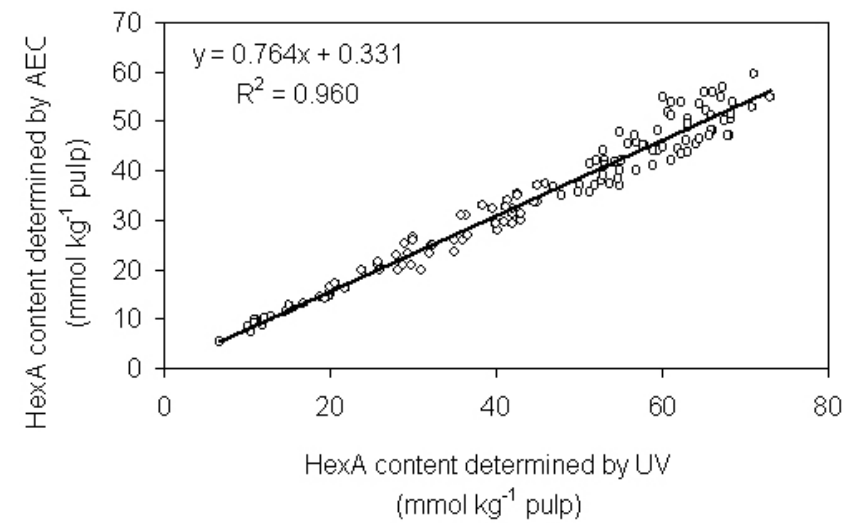

Figure 4. Relationship between HexA content determined by anion exchange chromatographic method and UV spectrophotometric in kraft pulps of E. globulus.

The reproducibility of UV and AEC techniques was evaluated in three groups of experiments, each one carried out in triplicate or quadruplicate for a selected kraft pulp using a confidence limit of $95 \%$. Very good reproducibility was found for both techniques at $p<0.05$. RSD was $2.1 \%$ and $1.4 \%$ for AEC and UV, respectively, indicating the high precision and good reproducibility of the methods (Table 4). Dhalman et al. ${ }^{16}$ using enzymatic hydrolysis and subsequent capillary electrophoresis, obtained RSD between $2.8 \%$ and $5.1 \%$. Chai et al. ${ }^{9}$ and Jiang et al. ${ }^{14}$ found RSD near to $2.0 \%$ based on five replicate determinations of the entire analytical process including sampling, acid hydrolysis and the analysis, indicating the high precision of their methods. Thus, we can confirm that the precision offered by the UV and AEC techniques is very close to other methods reported in the literature ${ }^{16}$. 
Table 4. Reproducibility of UV and AEC techniques.

\begin{tabular}{|c|c|c|c|c|c|c|}
\hline $\begin{array}{l}\text { Experiment } \\
\text { No. }\end{array}$ & $\begin{array}{l}\text { HexA content means (mmol kg } \\
\text { pulp }^{-1} \text { ) }\end{array}$ & $\mathbf{N}$ & SD & Variance & $\mathbf{F}$ & p-level \\
\hline AEC-1 & 35.84 & 4 & 0.49 & 0.24 & 0.36 & 0.71 \\
\hline AEC-2 & 35.45 & 4 & 0.94 & 0.88 & & \\
\hline AEC-3 & 35.45 & 3 & 0.71 & 0.50 & & \\
\hline Average & 35.59 & 11 & 0.69 & 0.48 & & \\
\hline UV-1 & 50.76 & 4 & 0.95 & 0.89 & 0.81 & 0.48 \\
\hline UV-2 & 50.64 & 4 & 0.33 & 0.11 & & \\
\hline UV-3 & 50.09 & 3 & 0.76 & 0.57 & & \\
\hline Average & 50.53 & 11 & 0.71 & 0.50 & & \\
\hline \multirow{2}{*}{ Methods } & \multicolumn{3}{|c|}{ HexA (mmol kg pulp $\left.{ }^{-1}\right)$} & \multirow{2}{*}{ Confid. $+95 \%$} & \multirow{2}{*}{ Variance } & \multirow{2}{*}{ RSD } \\
\hline & Average & Minimum & Maximum & & & \\
\hline $\mathrm{AEC}$ & 35.6 & 34.2 & 36.4 & 0.47 & 0.69 & 1.94 \\
\hline UV & 50.5 & 49.3 & 51.6 & 0.48 & 0.71 & 1.40 \\
\hline
\end{tabular}

HexA data measured by the AEC technique were $11-30 \%$ lower than those measured by UV technique. In order to compare, five pulps were analyzed by other HexA determination techniques, known as KTH and HUT. When comparing the data obtained by the four methods employed, these reported variations in HexA measurements. The highest HexA values were obtained with the UV technique; while the KTH, AEC and HUT methods provided HexA amounts that were $7-16 \%, 17-24 \%$ and $24-30 \%$ lower for the same set of pulps, respectively (Table 5). Similar results have been reported by Tenkanen et al. ${ }^{19}$ when comparing HexA determination by the KTH, VTT and HUT methods in unbleached and bleached softwood kraft pulps. Different results were obtained with the three methods. The highest values were obtained by KTH method, while the values obtained by the VTT and HUT methods were $5-10 \%$ and $14-25 \%$ lower that those obtained by KTH, respectively. No method for the analysis of HexA was clearly superior to the others according to the authors. Because reproducibility of all methods is relatively good, the results from any of the methods could result in a systematic error in the range of $10-30 \% 9,19$. However, in the quantification of HexA by the UV technique, a systematic error propagation from the KTH method could affect the results. The use of AEC allows direct measurement of HexA hydrolysis products avoiding this problem.

Table 5 shows that samples B, C and D with kappa number between 9 and 20 can be determined for all methods employed. However, sample $\mathrm{E}$ with kappa number 58, due to the high lignin content, presented problems in the determination the HexA content using the HUT method. The lignin dissolved from pulps during the acid hydrolysis in this method interferes with HexA quantification ${ }^{14}$, which could be a disadvantage for this technique since samples with high kappa number can not be determined by HUT method. On the other hand, the AEC technique could not be used in HexA determination in ECF bleached kraft pulp (sample A) because the presence of some residual chloride in the pulp affects the hydrolysis products' chromatographic signal. The main characteristics and comparison of AEC, UV, KTH and HUT methods regarding time to carry procedures, reproducibility, hydrolysis performance a quantification are showed in Table 6.
Table 5. Comparison between methods in the determination HexA in kraft pulps.

\begin{tabular}{|l|c|c|c|c|c|}
\hline \multirow{2}{*}{$\begin{array}{c}\text { Kraft } \\
\text { pulp }\end{array}$} & \multirow{2}{*}{$\begin{array}{c}\text { Kappa } \\
\text { number }\end{array}$} & \multicolumn{4}{|c|}{$\begin{array}{c}\text { HexA } \\
(\mathbf{m m o l} \text { kg pulp }\end{array}$} \\
\cline { 3 - 6 } ) \\
\hline A* & --- & $17.7 \pm 0.2$ & ----- & $15.1 \pm 0.1$ & $13.4 \pm 0.2$ \\
\hline B & $12.7 \pm 0.5$ & $62.4 \pm 0.6$ & $48.7 \pm 0.2$ & $52.8 \pm 0.6$ & $43.9 \pm 0.4$ \\
\hline C & $9.2 \pm 0.1$ & $25.9 \pm 0.4$ & $21.6 \pm 0.1$ & $24.2 \pm 0.1$ & $20.5 \pm 0.3$ \\
\hline D & $18.9 \pm 0.7$ & $44.5 \pm 0.3$ & $33.7 \pm 0.4$ & $40.5 \pm 0.6$ & $42.1 \pm 0.4$ \\
\hline E & $58.3 \pm 0.9$ & $14.7 \pm 0.4$ & $11.4 \pm 0.1$ & $12.4 \pm 0.2$ & $30.3 \pm 0.7$ \\
\hline
\end{tabular}

* Bleached kraft pulp (ECF)

Table 6. Main characteristics of HexA quantification by different analytical methods.

\begin{tabular}{|c|c|c|c|c|}
\hline & $\mathbf{U V}$ & AEC & KTH & HUT \\
\hline Hydrolysis time & $45 \mathrm{~min}$ & $180 \mathrm{~min}$ & $210 \mathrm{~min}$ & $60 \mathrm{~min}$ \\
\hline Analysis time & $<5 \min$ & $\sim_{\min } 25$ & $\sim 25 \mathrm{~min}$ & $<5$ min \\
\hline Reproducibility & Good & Good & Good* & Good* \\
\hline $\begin{array}{l}\text { Hydrolysis } \\
\text { efficiency of HexA }\end{array}$ & $\geq 95 \%$ & $\geq 95 \%$ & ND & Incomplete ** \\
\hline $\begin{array}{l}\text { Quantification of } \\
\text { hydrolysis products }\end{array}$ & $\underset{* * *}{\text { Indirect }}$ & Direct & Direct & Indirect $* * *$ \\
\hline
\end{tabular}

* According to the literature (not evaluated in this work); ** According to the literature (not evaluated in this work); *** Possible interference of other compounds during UV analysis; ND...not determined.

\section{CONCLUSIONS}

The reproducibility of UV and AEC techniques used for HexA quantification in kraft pulps of E. globulus was good. As indicated, a good agreement was observed between UV and AEC techniques with the others 
existent quantification techniques (HUT and KTH). It is difficult to establish which technique is the most accurate since reproducibility is good for both methods. In our opinion the use of chromatographic techniques which allows direct measurement of HexA hydrolysis products is more indicated and possibly the more reliable.

\section{ACKNOWLEDGEMENTS}

Financial support from FONDECYT (Grant 1050535) and CONICYT (M. Monrroy $\mathrm{PhD}$ fellowship) is gratefully acknowledged.

\section{REFERENCES}

1. A. Ebringerová, Z. Hromádková, T. Heinze, Adv Polym Sci. 186, 1, (2005).

2. J. Genco, N. Busayasakul, H. Medhora, W. Robbins, Tappi J. 4, 223, (1990).

3. J. Buchert, A. Teleman, V. Harjunpaa, M. Tenkanen, L. Viikari, T. Vuorinen, Tappi J. 78, 125, (1995).

4. M. Monrroy, R. Mendonça, J. Rodríguez, J.B. And, J. Freer, Appita J. 61, 212, (2008).

5. J.P.F. Simão, A.P.V. Egas, C.M.S.G. Baptista, M.G. Carvalho, J.A.A.M. Castro, Ind. Eng. Chem. Res. 44, 2990,(2005).
6. A.Teleman, V. Harjunpää, M. Tenkanen, J. Buchert, T. Hausalo, T. Drakenberg, T. Vuorinen, Carbohyd. Res. 272, 55, (1995).

7. T. Vuorinen, P. Fagerstrom, J. Buchert, M. Tenkanen, A. Teleman, J. Pulp Paper Sci. 25, 155, (1999).

8. X.S. Chai, Q. Luo, S.H. Yoon, J.Y. Zhu, J. Pulp Paper Sci. 27, 403, (2001b).

9. X. Chai, J. Zhu, i.J. L, J Pulp Paper Sci. 27, 165 (2001a).

10. G. Gellerstedt, J. Li, Carbohyd. Res. 294, 41 (1996).

11. J. Li, G. Gellerstedt, Carbohyd. Res. 302, 213 (1997).

12. M. Pereira, R. Melo, C. Daza, Celulosa y Papel 3, 14 (2003).

13. Z.H. Jiang, J. Bouchard, R. Berry, Holzforschung 60, 137 (2006).

14. Z.H. Jiang, A. Audet, J. Sullivan, B. Van Lierop, R. Berry, J. Pulp Paper Sci. 27, 92 (2001).

15. M. Tenkanen, T. Hausalo, M. Siikaaho, J. Buchert, L. Viikari, Proc. 8th Intl. Symp.Wood Pulping Chem, Helsinki, Finland 3 (1995).

16. O. Dahlman, A. Jacobs, A. Liljenberg, A.I. Olsson, J. Chromatogr. A, 891, 157 (2000)

17. Teleman, T. Hausalo, M. Tenkanen, T. Vuorinen, Carbohyd. Res. 280, 197 (1996).

18. R.E. Bruns, I.S. Scarminio, N.B. Barros, Elsevier Science, 1ed; Data Handling in Science and Technology 5, 245 (2001).

19. M. Tenkanen, G. Gellerstedt, T. Vuorinen, A. Teleman, M. Perttula, J. Li, J. Buchert, J. Pulp Paper Sci. 25, 306 (1999). 